Décadrages Décadrages

cinéma, à travers champs Cinéma, à travers champs

$7 \mid 2006$

Stephen Dwoskin

\title{
Die Vogelpredigt (Clemens Klopfenstein, 2005)
}

\section{Raphaël Pasche}

\section{(2) OpenEdition}

\section{Journals}

Édition électronique

URL : https://journals.openedition.org/decadrages/500

DOI : $10.4000 /$ decadrages. 500

ISSN : 2297-5977

\section{Éditeur}

Association Décadrages

\section{Édition imprimée}

Date de publication : 10 avril 2006

Pagination : 125

ISBN : 978-29700582-3-6

ISSN : 2235-7823

\section{Référence électronique}

Raphaël Pasche, «Die Vogelpredigt (Clemens Klopfenstein, 2005) », Décadrages [En ligne], 7| 2006, mis en ligne le 31 janvier 2014, consulté le 03 avril 2022. URL : http://journals.openedition.org/ decadrages/500; DOI : https://doi.org/10.4000/decadrages.500

Ce document a été généré automatiquement le 3 avril 2022.

(B) Décadrages 


\title{
Die Vogelpredigt (Clemens Klopfenstein, 2005)
}

\author{
Raphaël Pasche
}

En dépit d'une image négligée que le discours du film voudrait justifier en arguant du manque de moyens financiers, Die Vogelpredigt présente un intéressant questionnement sur les figures de l'acteur et de l'auteur. Le film met en scène Max Rüdlinger et Polo Hofer, ainsi que Clemens Klopfenstein dans leurs propres rôles d'acteurs et de réalisateur. Trio uni par plusieurs collaborations, Rüdlinger et Hofer ont aussi une carrière extracinématographique (star de série TV et musicien) avec laquelle le film dialogue. On savoure aussi la déconstruction de l'icône Ursula Andress, ancienne James Bond girl qui, aujourd'hui septuagénaire, incarne la Vierge Marie. Bien que le réalisateur-personnage meure et que la caméra tombe au sol - jeu hypertextuel (on pense à des films comme C'est arrivé près de chez vous ou Le Projet Blair Witch) permettant de s'interroger sur les genres cinématographiques-, le réalisateur de Vogelpredigt continue à tourner, affirmant ainsi en fin de compte sa suprématie. A la suggestion de Max qui propose de faire un film de genre populaire et vendeur, avec du sexe et un crime,Klopfenstein répond par un «film d'auteur ». 